P-ISSN: 2541-6960; E-ISSN: 2549-8754

Yupa: Historical Studies Journal

Vol. 4 No. 1, 2020 (1-8)

http://jurnal.fkip.unmul.ac.id/index.php/yupa

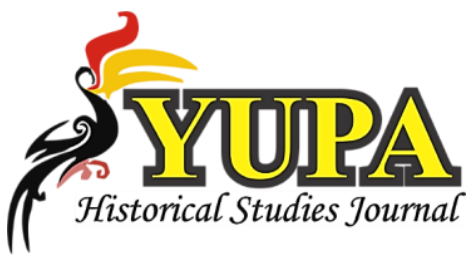

\title{
Model Pembelajaran IPS Terintegrasi Nilai-Nilai Catur Guru sebagai Civic Intelligence di Bali
}

\author{
Lianda Dewi Sartika' ${ }^{1}$, Hermanu Joebagio ${ }^{2}$, Susanto ${ }^{3}$ \\ ${ }^{1}$ Universitas Sebelas Maret, Surakarta, Indonesia \\ 2 Universitas Sebelas Maret, Surakarta, Indonesia \\ 3 Universitas Sebelas Maret, Surakarta, Indonesia \\ 1lianda.dewi23@gmail.com, 2hermanu.joebagio@gmail.com, ${ }^{3}$ santosastrauns@yahoo.co.id
}

\begin{tabular}{ccc}
\hline Received & Accepted & Published \\
$19 / 06 / 2020$ & $28 / 08 / 2020$ & $10 / 09 / 2020$ \\
\hline
\end{tabular}

\begin{abstract}
Local material that is relevant to the learning of Social Sciences (IPS) strongly supports the achievement of learning objectives and national education goals. Therefore, the Government of the Republic of Indonesia has regulated it by making Law Number 32 the Year 2013 regarding potential local content in learning. Junior High School PGRI 1 Denpasar, Bali Province has followed up with developing integrated social studies learning of Catur Guru Values as Civic Intelligence. This research was conducted in December 2019 to February 2020 using qualitative research methods with a case study approach. Data collection methods used were interviews, observation, and document analysis. The results showed this learning model was successful with the formation of Civic Intelligence in students due to the carrying capacity and intersection of Catur Guru Values with social studies and national education.
\end{abstract}

Keywords: Social Science Education, Catur Guru Values, Civic Intelligence, Bali

\begin{abstract}
Abstrak Materi lokal yang relevan dengan pembelajaran Ilmu Pengetahuan Sosial (IPS) sangat mendukung ketercapaian tujuan pembelajaran dan tujuan pendidikan nasional. Oleh karena itu, Pemerintah Republik Indonesia telah mengatur dengan membuat regulasi Undangundang Nomor 32 Tahun 2013 mengenai potensi muatan lokal dalam pembelajaran. SMP PGRI 1 Denpasar Provinsi Bali telah menindaklanjuti dengan mengembangkan pembelajaran IPS terintegrasi nilai-nilai Catur Guru sebagai kecerdasan warganegara. Penelitian ini dilakukan pada Desember 2019 hingga Februari 2020 dengan mengunakan metode penelitian kualitatif dengan pendekatan studi kasus. Metode pengumpulan data yang digunakan adalah wawancara, observasi, dan analisis dokumen. Hasil penelitian menunjukkan adanya daya dukung dan intersection nilai-nilai Catur Guru, IPS, pendidikan nasional serta juga Civic Intelligence menjadi kunci keberhasilan model pembelajaran IPS terintegrasi nilai-nilai Catur Guru. Hal ini dikarenakan nilai-nilai Catur Guru sangat relevan dan dekat dengan lingkungan peserta didik. Dukungan dari pemerintah, satuan pendidikan serta daya inovatif-kreativitas guru IPS memegang peranan penting untuk mencapai ini semua.
\end{abstract}

Kata kunci: Ilmu Pengetahuan Sosial, Nilai-Nilai Catur Guru, kecerdasan warganegara, Bali 


\section{PENDAHULUAN}

Dewasa ini, Pemerintah Republik Indonesia telah memberikan otoritas yang besar kepada para pendidik dan satuan pendidikan dalam mengembangkan perangkat pembelajarannya. Kementrian Pendidikan dan Kebudayaan (Kemendikbud) hanya memberikan panduan rencana pembelajaran pada suatu dan/atau kelompok mata pelajaran/tema tertentu yang mencakup standar kompetensi, kompetensi dasar, materi pokok/pembelajaran, kegiatan pembelajaran, indikator pencapaian kompetensi untuk penilaian, penilaian, alokasi waktu, dan sumber belajar yang sering disebut sebagai silabus. Oleh karena itu, guru dan satuan pendidikan diharapkan untuk dapat mengembangkan perangkat pembelajaran khususnya adalah Rencana Pelaksanaan Pembelajaran (RPP) secara kreatif, inovatif dan relevan. Pengembangan Rencana Pelaksanaan Pembelajaran (RPP) secara kreatif, inovatif dan relevan tujuannya agar peserta didik dalam proses belajarnya mampu mencapai tujuan pembelajaran. Karena banyak dari para peserta didik mengalami kesulitan dalam mencapai tujuan pembelajaran akibat materi yang tidak relevan dalam kehidupan sehari-hari.

Oleh sebab itu, guru dan satuan pendidikan SMP PGRI 1 Denpasar merancang dan telah menerapkan srategi pembelajaran IPS yang mengintegrasikan nilai-nilai Catur Guru. Catur Guru adalah ajaran dalam agama Hindu yang mengandung nilai-nilai luhur dan terdapat dalam pustaka-pustaka suci Hindu, yaitu pada kitab suci Weda Sruti dan Smrti. Disamping itu, ada banyak sastra-sastra Hindu seperti Mahabharata, Ramayana, Bharatayuddha, Arjuna Wiwaha, Sutasoma, dsb, yang didalamnya mencerminkan tentang implementasi nilai-nilai Catur Guru. Selain merupakan nilai-nilai yang terdapat dalam kitab suci Weda dan kesusasteraan Hindu, ajaran Catur Guru telah diwariskan oleh para leluhur hingga generasi saat ini.

Nilai-nilai Catur Guru bukan hanya lahir, berkembang, dan hidup dalam masyarakat Hindu di Bali, tetapi juga telah menjadi landasan filosofis masyarakat Hindu karena ajaran Catur Guru dapat membentuk karakter serta kepribadian generasi muda di Bali. Catur Guru terdiri dari dua kata, yaitu kata "Catur" yang artinya empat dan juga kata "Guru". Jadi, dalam kepercayaan Hindu ada empat guru yang harus dihormati. Hal ini dijelaskan melalui nilai-nilai yang terkandung dalam ajaran Catur Guru, di antaranya Guru Swadyaya (Tuhan), Guru Wisesa (Pemimpin/Pemerintah), Guru Pengajian (Guru di Sekolah), dan Guru Rupaka/Reka (Orangtua). Melalui nilai-niai dalam ajaran Catur Guru ini, diharapkan bahwa manusia akan 
senantiasa menghormati keempat guru tersebut. Selain itu, nilai-nilai Catur Guru juga sangat relevan dan saling berkaitan dengan tujuan pembelajaran IPS dan tujuan pendidikan nasional.

Selanjutnya tujuan pengajaran IPS yang merupakan mata pelajaran wajib dan diajarkan di Sekolah Menengah Pertama (SMP) mempunyai tujuan untuk membentuk peserta didik sebagai warga negara yang baik, memiliki kemampuan untuk memahami dan memecahkan masalah sosial, membangun komitmen terhadap nilai-nilai kemanusiaan, memiliki sikap saling menghargai, dan ikut mengembangkan nilai-nilai luhur. Sedangkan tujuan pendidikan nasional yang tercantum pada UU No. 20 Tahun 2003 tentang Sistem Pendidikan Nasional Bab II Pasal 3 menjelaskan mengenai tujuan dari pendidikan nasional, yaitu: "Pendidikan nasional bertujuan untuk berkembangnya potensi peserta didik agar menjadi manusia yang beriman dan bertakwa kepada Tuhan Yang Maha Esa, berakhlak mulia, sehat, berilmu, cakap, kreatif, mandiri, dan menjadi warga negara yang demokratis serta bertanggung jawab".

Pentingnya strategi yang tepat dalam mendukung ketercapaian tujuan pembelajaran IPS dan pendidikan nasional patut dipikirkan oleh guru dan satuan pendidikan. Pengintegrasian nilai-nilai Catur Guru ke dalam mata pelajaran IPS di SMP sudah sangat relevan dengan tujuan pendidikan nasional dan tujuan pembelajaran IPS. Seperti yang dilakukan oleh SMP PGRI 1 Denpasar Provinsi Bali yang telah menerapkan pembelajaran IPS terintegrasi nilai-nilai Catur Guru sebagai Civic Intelligence. Artinya pembelajaran IPS bukan hanya memuat materi lokal yang dekat dengan peserta didik, dan mendukung tujuan pendidikan nasional akan tetapi mempunyai capaian khusus, yakni Civic Intelligence.

Civic Intelligence merupakan kemampuan seseorang untuk memainkan peran dirinya secara proaktif sebagai warga negara dan warga masyarakat dalam tata kehidupan yang kompleks dengan berbasiskan identititas normatif menghadapi berbagai persoalan kehidupan yang dialaminya. Jika kecerdasan kewarganegaraan ini tumbuh subur dalam diri seseorang, maka akan menciptakan figur warga negara yang baik (good citizenship).

Dengan demikian, kunci dari pembentukan warga negara yang baik adalah Civic Intelligence (Masrukhi, 2018). Berangkat dari pengertian Civic Intelligence tersebut dapat dipahami bahwa ada keterkaitan (intersection) dengan tujuan pendidikan IPS dan tujuan pendidikan nasional serta Catur Guru. Oleh karena itu, penulisan ini mengkaji bagaimana model pembelajaran IPS terintegrasi nilai-nilai Catur Guru sebagai Civic Intelligence di SMP PGRI 1 Denpasar Provinsi Bali. 


\section{METODE}

Tulisan ini mengunakan metodologi penelitian kualitatif deskriptif dengan pendekatan studi kasus. Studi kasus adalah penelitian yang dilakukan secara intensif dan mendalam terhadap suatu lembaga, organisasi, atau gejala-gejala tertentu. (Muh. Fitrah \& Luthfiyah, 2017) menyatakan proses pengumpulan data penelitian disesuaikan dengan jenis penelitian. Sumber data menurut (Moleong, 1988) dan (Nasution, 1988) yang dimaksud adalah:

1) Kata-kata diperoleh secara langsung atau tidak langsung melalui wawancara dan observasi.

2) Dokumen berupa kurikulum, Satuan Pembelajaran, Rencana Pelajaran.

3) Situasi yang berhubungan dengan kegiatan subjek penelitian dan masalah penelitian seperti dalam proses belajar mengajar, situasi belajar di perpustakaan dan situasi di lingkungan sekolah.

Observasi yang dilakukan oleh peneliti adalah mengamati pembelajaran IPS pada guru mata pelajaran IPS yang dilakukan sebagai berikut: Mendesain materi pembelajaran nilai-nilai Catur Guru dalam mata pelajaran IPS sebagai Empowering Civic Intelligence peserta didik, dengan desain perencanaan, pelaksanaan dan tindak lanjut pembelajaran yang dilakukan guru.

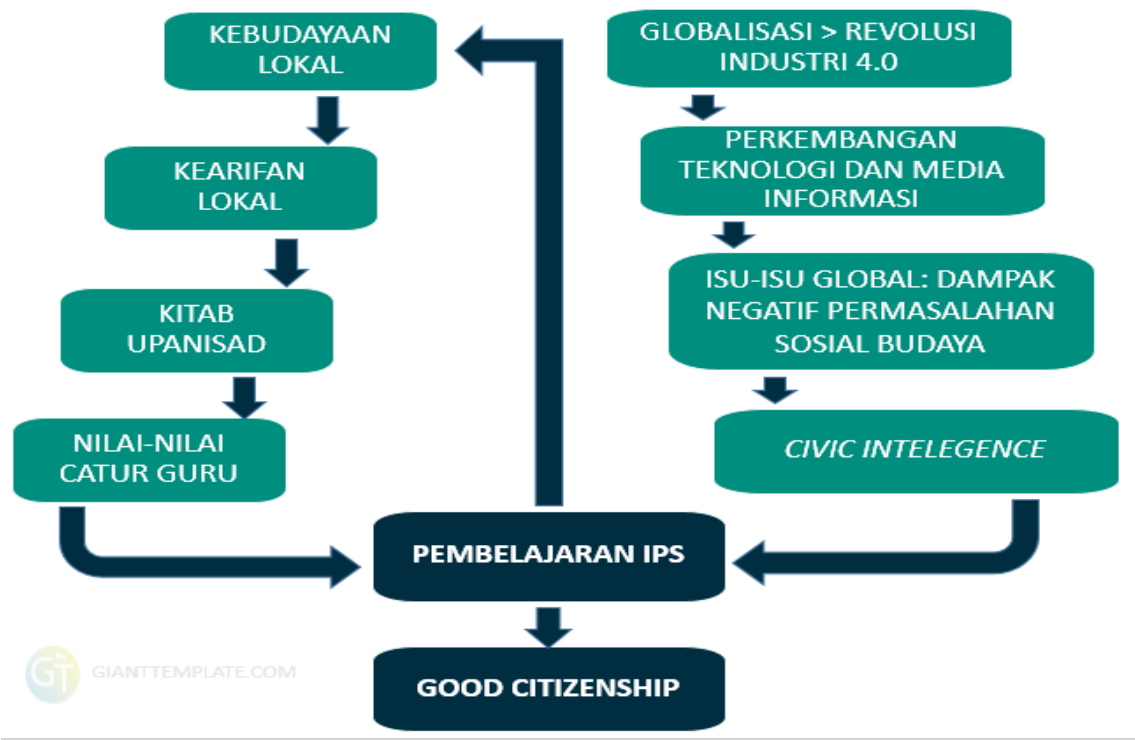

Gambar 1.1 Kerangka Berpikir Implementasi Pembelajaran IPS Terintegrasi Nilai Catur Guru 


\section{HASIL DAN PEMBAHASAN}

\section{Ilmu Pengetahuan Sosial (IPS)}

Mata pelajaran IPS merupakan mata pelajaran wajib dan diajarkan di Sekolah Menengah Pertama (SMP) termasuk di SMPN PGRI 1 Denpasar. Mata Pelajaran IPS memiliki karakteristik, yaitu: (a) IPS merupakan keterpaduan dari unsur-unsur geografi, sejarah, ekonomi, dan sosiologi; (b) Kompetensi Inti (KI) dan Kompetensi Dasar (KD) IPS berasal dari struktur keilmuan geografi, sejarah, ekonomi, dan sosiologi, yang dikemas sedemikian rupa sehingga dapat dikembangkan menjadi pokok bahasan atau topik (tema) tertentu; (c) KI dan KD IPS juga menyangkut berbagai masalah sosial yang dirumuskan dengan pendekatan interdisipliner dan multidisipliner. Ilmu sosial adalah salah satu mata pelajaran pembelajaran, yang dirancang untuk memberikan yang baru pengetahuan dan pengalaman sosial kepada siswa. Dengan pengetahuan dan pengalaman ini, para siswa dapat meningkatkan keterampilan sosialisasi dan pengakuan akan kehadiran mereka dari yang lain. Mengingat pentingnya pembelajaran ilmu sosial, maka para guru harus dapat menyampaikan materi pembelajaran secara efektif untuk mencapai tujuan belajar (Rahayu et al., 2018).

\section{Nilai-nilai Catur Guru}

Nilai-nilai dari Catur Guru ini dilakukan melalui perbuatan-perbuatan nyata dan konkret yang disebut dengan Bhakti.(Sukartha, I Nengah, I Nyoman Suparwa, I Putrayasa, 2015) Berikut ini merupakan wujud Bhakti kepada Catur Guru:

1. Bhakti kepada Guru Swadyaya dapat dilakukan dengan rajin beribadah, menjalankan ajaran agama, mengunjungi tempat suci, menghindari perbuatan dosa, dsb.

2. Bhakti kepada Guru Rupaka diwujudkan dengan senantiasa berbakti kepada kedua orangtua, tidak melawan orangtua, menghormati orangtua kita, dll.

3. Bhakti kepada Guru Wisesa dapat dilakukan melalui menghormati pemerintah, menaati perintah atau hukum yang berlaku, dan melakukan pengabdian demi kesejahteraan masyarakat.

4. Bhakti kepada Guru Pangajian dapat diwujudkan melalui hormat, taat, dan patuh terhadap nasehat guru, menaati peraturan sekolah, belajar dengan sungguh-sungguh, dan mengamalkan ilmu pengetahuan demi kepentingan manusia.

\section{Kecerdasan Warganegara (Civic Intelligence)}

Civic Intelligence adalah tata nilai yang berada pada ranah afeksi pada diri warga negara. Civic Intelligence yang berada pada ranah afeksi ini meliputi cita-cita dan tujuan yang 
dianut atau diutarakan seseorang, aspirasi yang dinyatakan, sikap yang ditampilkan atau ditampakkan, perasaan yang diutamakan, perbuatan yang dilakukan, serta kekhawatirankekhawatiran (worries) yang diutarakan atau tampak. (Fraenkel, 2007) Terdapat tujuh kecakapan yang harus dibangun untuk membentuk kecerdasan kewarganegaraan (Civic Intelligence); yaitu civic knowledge, civic disposition, civic skills, civic confidence, civic commitment, civic competence, dan civic culture. Tujuh kecakapan tersebut haruslah terintegrasi secara harmonis dalam aktifitas berpikir, bersikap, dan bertindak sebagai insan warga negara Indonesia, yang dilandasi oleh nilai-nilai kewarganegaraan (civic values). Ketujuh aspek Civic Intelligence tersebut merupakan satu kesatuan dalam proses kejiwaan peserta didik. Civic knowledge berkenaan dengan pengetahuan dan pemahaman akan kedudukan dirinya sebagai warga negara, yang memiliki hak dan kewajiban berdasar nilainilai konstitusi negara (Winataputra, 2001).

Integrasikan nilai-nilai Catur Guru pada pembelajaran IPS dapat dilakukan dengan model integrasi berdasarkan potensi utama. Rasional keterpaduan IPS dapat dikembangkan melalui topik yang didasarkan pada potensi utama yang ada di wilayah setempat.(WIDARWATI, 2016) Selain itu dukungan Presiden Republik Indonesia melalui Peraturan Pemerintah Republik Indonesia Nomor 32 Tahun 2013 Tentang Perubahan atas Peraturan Pemerintah Nomor 19 Tahun 2005 Tentang Standar Nasional Pendidikan Bagian Keenam Muatan Lokal Pasal 77N menjelaskan bahwa:

(1) Muatan lokal untuk setiap satuan pendidikan berisi muatan dan proses pembelajaran tentang potensi dan keunikan lokal.

(2) Muatan lokal dikembangkan dan dilaksanakan pada setiap satuan pendidikan.

Pada hakikatnya pembangunan karakter bangsa ini mengarah pada penciptaan suatu masyarakat Indonesia yang menempatkan demokrasi dalam kehidupan berbangsa dan bernegara sebagai titik sentral. Hal tersebut juga tercantum dalam tujuan pendidikan nasional, yakni menjadi warga negara yang demokratis. Seturut dengan itu, tujuan pendidikan IPS juga mempersiapkan peserta didik menjadi warga negara yang baik. Tujuan itu sebenarnya sudah ada dalam ajaran Catur Guru, saat peserta didik dapat mengamalkan nilainilai Catur Guru dalam kehidupannya maka niscaya peserta didik tersebut dapat mewujudkan tuperaturan pejuan dan harapan dari bangsa dan negara ini. 


\section{Nilai-nilai Catur Guru sebagai Empowering Civic Intelligence}

1. Konsep Catur Guru: Catur Guru terdiri dari empat macam guru yang harus dihormati, yaitu Guru Swadyaya (Tuhan), Guru Rupaka (orangtua), Guru Pangajian (Guru di Sekolah), dan Guru Wisesa (Pemerintah). Nilai-nilai Catur Guru ini telah melekat erat dari generasi ke generasi yang ditanamkan oleh masyarakat Hindu.

2. Catur Guru merupakan cara pandang dan filsafat hidup yang dijunjung tinggi oleh masyarakat Hindu. Dalam kehidupan di dunia ini masyarakat Hindu sangat menghormati tiga guru atau disebut sebagai Tri Guru yang ada dalam Catur Guru, di antaranya Guru Rupaka (orangtua), Guru Pangajian (Guru di Sekolah), dan Guru Wisesa (Pemerintah). Sedangkan Guru Swadyaya (Tuhan) dianggap sebagai guru sejati, karena apabila sebagai manusia sudah melaksanakan bhakti kepada Guru Swadyaya, maka sudah pasti akan berbakti kepada Tri Guru tersebut.

3. Catur Guru berfungsi sebagai pedoman hidup masyarakat Hindu untuk mempertahankan nilai-nilai yang sudah ada sejak dahulu dalam mengatur pola pikir dan pola perilaku manusia.

4. Melalui aktualisasi nilai-nilai Catur Guru ini, maka akan tercipta masyarakat yang memiliki integritas, nasionalis, taat pada peraturan dan hukum yang berlaku, serta berbudi pekerti luhur.

Hasil integrasikan nilai-nilai Catur Guru dalam pembelajaran IPS sebagai Civic Intelligence diwujudkan dalam sebuah Rencana Pelaksanaan Pembelajaran (RPP) yang digunakan oleh guru IPS di SMP PGRI 1 Denpasar Bali.

\section{KESIMPULAN}

Melalui pengembangan perangkat pembelajaran dan integrasi materi lokal Catur Guru yang relevan dengan pembelajaran IPS telah membantu peserta didik dan satuan pendidikan (sekolah) untuk mencapai tujuan pembelajaran IPS dan pendidikan nasional. Bahkan model pembelajaran yang dikembangkan oleh SMP PGRI 1 Denpasar Provinsi Bali tersebut juga berhasil membentuk peserta didik agar memiliki Civic Intelligence. Dukungan dari pemerintah dan satuan pendidikan serta daya inovatif-kreativitas guru IPS memegang peranan penting untuk mencapai ini semua. 


\section{REFERENSI}

Fraenkel. (2007). Developing the Civic Society: The Role of Civic Education. Englewood Cliffs, Inco.

Masrukhi. (2018). PENGEMBANGAN CIVIC INTELLEGENCE BERBASIS KEGIATAN EKSTRA KURIKULER DI SEKOLAH DASAR. INTEGRALISTIK, I, 14-28.

Moleong, L. J. (1988). Metode Penelitian Kualitatif. Remaja Rosdakarya.

Muh. Fitrah \& Luthfiyah. (2017). Metodologi penelitian: penelitian kualitatif, tindakan kelas \& studi kasus (cetakan pe). CV Jejak.

Nasution, S. (1988). Metode Penelitian Naturalistik- Kualitatif. Tarsito.

PERATURAN PEMERINTAH REPUBLIK INDONESIA NOMOR 32 TAHUN 2013 TENTANG PERUBAHAN ATAS PERATURAN PEMERINTAH NOMOR 19 TAHUN 2005 TENTANG STANDAR NASIONAL PENDIDIKAN DENGAN, 1 (2013).

Rahayu, A., Sariyatun, \& Nunuk Suryani. (2018). The Implementation of Group Investigation with Audio Visual Learning Media to Improve Student 's Learning Achievement and Student 's Attitude of Love the Homeland on Social Science Learning in Sambirejo 2 Junior High School. Yupa: Historical Studies Journal, 2(2). https://doi.org/https://doi.org/10.30872/yupa.v2i2.120

Sukartha, I Nengah, I Nyoman Suparwa, I Putrayasa, I. W. T. (2015). Pendidikan Agama Hindu untuk Perguruan Tinggi.

WIDARWATI. (2016). GURU PEMBELAJAR MODUL MATA PELAJARAN ILMU PENGETAHUAN SOSIAL (IPS) SEKOLAH MENENGAH PERTAMA (SMP). PUSAT PENGEMBANGAN DAN PEMBERDAYAAN PENDIDIK DAN TENAGA KEPENDIDIKAN PENDIDIKAN KEWARGANEGARAAN DAN ILMU PENGETAHUAN SOSIAL (PPPPTK PKn DAN IPS).

Winataputra, U. S. (2001). Jatidiri Pendidikan Kewarganegaraan Sebagai Wahana Sistemik Pendidikan Demokrasi (Suatu Kajian Konseptual Dalam Konteks Pendidikan IPS). DISERTAS JATIDIRI PENDIDIKAN KEWARGANEGARAAN SEBAGAI WAHANA SISTEMIK PENDIDIKAN DEMOKRASI, 1-593. http://repository.ut.ac.id/2872/1/40115.pdf 